\title{
Statistical Analysis and Corrosion Assessment of Nigeria Steel Rebars: Case Study South-West, Nigeria
}

\author{
Igibah Ehizemhen C*, Agashua Lucia O, Sadiq Abubakar A \\ Department of Civil Engineering, University of Abuja, Nigeria
}

Received September 7, 2019; Revised October 24, 2019; Accepted November 4, 2019

\begin{abstract}
Copyright $\mathrm{O} 2019$ by authors, all rights reserved. Authors agree that this article remains permanently open access under the terms of the Creative Commons Attribution License 4.0 International License
\end{abstract}

\begin{abstract}
Corrosion assessment of rebars is very essential to predict the behaviour of reinforced concrete structures in different host environmental conditions. It also highlights the limitations of the local rebars. From the analysis, the severity of aqueous solutions on rebars was in the order $\mathrm{H}_{2} \mathrm{SO}_{4}>\mathrm{HCl}>\mathrm{Na}_{2} \mathrm{SO}_{4}>\mathrm{H}_{2} \mathrm{O}$ for both imported and local bars, whereas the ratio of the severity of local to imported steel rebars in water, $\mathrm{Na}_{2} \mathrm{SO}_{4}, \mathrm{H}_{2} \mathrm{SO}_{4}$ and $\mathrm{HCl}$ were $1.59,1.26,1.79$ and 1.20 respectively. All the steel bars experienced deterioration due to mass loss, characterized by colour change in all the solutions except $\mathrm{NaOH}$ solution where no visible reaction took place as $\mathrm{H}^{+}$ in the aqueous solution could not react with $\mathrm{Na}^{+}$which is higher in the electrochemical series. Also, there is a smaller degree of uncertainty in the imported reinforcing bars size with $\mathrm{COV}$ in the range of 0.06 to 0.20 and the local reinforcing bars in the range of 0.25 to 0.75 for the same diameter size range. To end with, the findings would address permissible nominal cover for different host environment to prevent deterioration of steel reinforcement under chemical attack and in water.
\end{abstract}

Keywords Corrosion, Steel Bars, Lagos, Water, Sodium Sulphate

\section{Introduction}

Corrosion of reinforcement in concrete structure started from the period little damage occurs, such as diffusion of chlorides towards the reinforcement with a propagation phase which initiated damages, besides progress after the corrosion threshold had been exceeded and corrosion has been initiated (Balogh and Vigh 2013; Bellis 2011). The insidious nature of steel corrosion makes effective repairs expensive if remedial work is only contemplated once significant damage occurs (Castro et al. 2002; Clifton et al. 1999). Clear understanding of mechanics of reinforced concrete structures helps in understanding the intricacy involved with the characterization of rebars (Ede 2010; Erhard 2006; Basu 2004) Moreover, basic knowledge on manufacturing process of steel helps in appreciating various facets of the characterization (Chahrour and Soudki 2005; Kosmtka et al. 2003). Locally manufactured reinforcing steel bars from scrap metal are becoming very common in Nigeria in particular and Africa in general, therefore special attention must be given to the quality of the available reinforcement steel of high yield grades produced and used in the Nigerian construction industry (Harald et al. 2013; Phillips 1998). In developing countries such as Nigeria where imported steel manufacture to world best standards is very expensive, milling companies and private individuals have taken up the challenge to re-cycle obsolete vehicle, machine metal parts and household metal waste for the production of structural and reinforcing steel (Yeon et al. 2007; Kayal and Zhu 2005; Phillips 1998). The typical registered indigenous steel rebar manufacturing industries that use scraps as their major raw materials for producing steel include Continental Iron and Steel Company (CISCO) Ikeja, Lagos, Universal Steel Company Ikeja, Lagos, Sun Flag Nigeria Ltd, Ikorodu, Lagos, Unique Steel Industries, Ltd, Lekki, Lagos, Nigerian Spanish Engineering Ltd, Kano, African Steel Nig. Ltd, Ikorodu, Lagos among several others. In fact, preliminary investigations revealed that there are scores of such local steel companies operating in Nigeria though not registered. Moreover, the steel reinforcing bar required for structural concrete that is partly produced by the country's inland rolling mills while the balance is sourced through import. The importation is carried out mostly by private entrepreneurs and the quality of such imported product is not always sure as they are essentially brought in from different sources without any thorough standardization process regarding their structural properties (Kankam and Adom-Asamoah 2002; Kaushik and Singh 2002; Phillips 1998). Hence, differences are bound to arise in the strengths, and possibly, geometry of steel assumed in 
design and those used for actual construction, unless tests are carried out on every batch of imported steel delivered on construction site (Harald et al. 2013; Hashemi 2006; Clifton and Marthey 1983). With the near collapse of the government-owned rolling mills and dwindling performance of the privatized counterparts in an unfriendly economy, influx of steel rebars from questionable sources is the order of the day in Nigerian markets (Alo et al. 2017; Phillips 1998; NIS 1992).

\section{Methods}

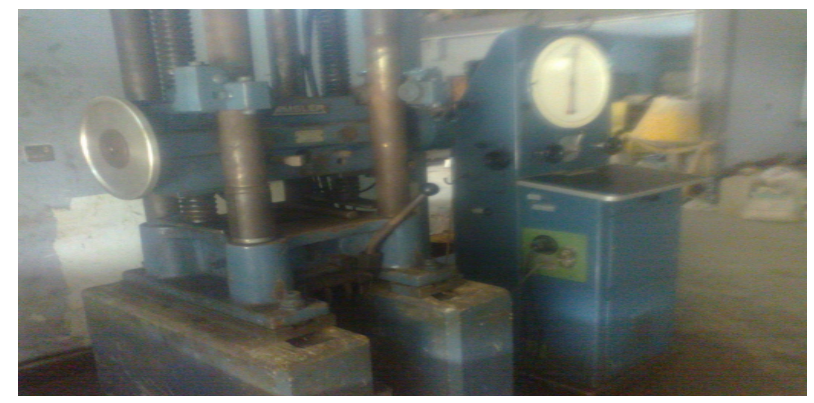

Figure 1. Avery Universal Testing Machine

\section{Result and Discussion}

High yield reinforcing steel bars were studied throughout the investigation at the Structural Engineering Laboratory of the Department of Civil Engineering, University of Lagos. With the aid of Vernier caliper the diameter of the specimen of $600 \mathrm{~mm}$ long was measured at several points along its length in order to determine the real size of specimen. Using the jig and punch, gauge-mark of $100 \mathrm{~mm}$ was made on each specimen. The specimen was then inserted into the Avery Universal Testing Machine
(UTM) with maximum capacity of $500 \mathrm{kN}$ shown in Figure 1 and a small load applied to take up the slack. A gradually increasing load was applied while taking the readings of load and extension at regular intervals of load using the dividers to measure the extension until the specimen fractures. The maximum load and the fracture load were recorded. The broken specimen will then be removed from the machine and the diameter at the neck measured. The two parts were placed together and the final length over the original gauge length measured with steel rule.

\subsection{Statistical Analysis}

The data as indicated in Table 1 gives the results during the size distribution survey of rebar in Lagos the foremost commercial city in the southwest. The diameters of all the sample of steel in the market in this area were measured using Vernier caliper. The statistical distribution of steel rebars in each study area is summarized in Table 1. All the parameters that consider for the steel rebars of range 10 $\mathrm{mm}$ to $25 \mathrm{~mm}$ are the mean $(\bar{x})$, standard deviation $(\sigma)$, variance $(\sigma 2)$ and the coefficient of variation $(\mathrm{COV})$. The coefficient of variation gives the most reasonable consideration, and it shows the percentage of standard deviation to the mean. It is obvious that in Lagos metropolis, the mean bar sizes for the different diameter of rebars considered for the imported are higher in diameter than the corresponding local type, with a very small margin. Also, there is a smaller degree of uncertainty in the imported reinforcing bars size having $\mathrm{COV}$ in the range of 0.06 to 0.20 and the local reinforcing bars in the range of 0.25 to 0.75 for the same diameter size range. Therefore, from the analysis, imported bars in relation to the sizes specified by British standard can still be considered for structural purposes, though not without proper assessment of the tensile strength properties.

Table 1. Statistical analysis of size distribution in Lagos city

\begin{tabular}{|c|c|c|c|c|c|}
\hline Steel bars & $\operatorname{Mean}(\bar{x})$ & & & & \\
\hline & Y10 & $\overline{Y 12}$ & $\overline{Y 16}$ & Y20 & Y25 \\
\hline Local & 9.78 & 11.7 & 15.6 & 19.82 & 24.7 \\
\hline Imported & 9.98 & 11.8 & 15.8 & 19.96 & 24.8 \\
\hline & Standard d & on $(\sigma)$ & & & \\
\hline Local & 0.072 & 0.064 & 0.096 & 0.064 & 0.064 \\
\hline Imported & $\begin{array}{l}0.0098 \\
\text { Coefficient }\end{array}$ & $\begin{array}{l}0.032 \\
\text { riation (\%) }\end{array}$ & 0.033 & 0.013 & 0.033 \\
\hline Local & 0.76 & 0.54 & 0.62 & 0.33 & 0.26 \\
\hline Imported & 0.10 & 0.21 & 0.21 & 0.07 & 0.14 \\
\hline Colours & $\mathrm{H}_{2} \mathrm{SO}_{4}$ & $\mathrm{Na}_{2} \mathrm{SO}_{4}$ & HCL & $\mathrm{NaOH}$ & $\mathrm{H}_{2} \mathrm{O}$ \\
\hline Initial Colour & Pale green & deep brown & brownish & N/A & Slippery \\
\hline Final Colour & Brownish & brownish & reddish brown & Slippery & brownish \\
\hline
\end{tabular}




\subsection{Corrosion Effect}

Corrosion of high yield steel of both imported and local due to immersion in drinkable water was observed. There are deposits of brown particles at the bottom of the container used at the end of the 6 weeks. Then, there was loss of weight in both imported and local steel. The mean of the weight loss of imported steel was $0.65 \mathrm{~g}$ while that of local steel rebars $0.80 \mathrm{~g}$. Also it can be observed that the rate of mass loss was more obvious in local steel rebar than imported steel. The mass loss was more pronounced in local steel after 2nd week while that of imported shows steel increasing after 4 th week. The corrosion observed in terms of colour change is summarized in Table 1, while the extent of deterioration due to corrosion in terms of percentage mass loss is summarized in Figures 4 and 7. Weekly durability assessment of the rebar specimens was evaluated to determine the mass loss and the mechanical properties when fully immersed in distilled water, and 5\% solution of $\mathrm{H}_{2} \mathrm{SO}_{4}, \mathrm{HCl}, \mathrm{NaOH}, \mathrm{Na}_{2} \mathrm{SO}_{4}$ in soluble water over a total period of six weeks. The deterioration due to corrosion expressed as a function of mass loss increased curvilinearly with time of exposure. The severity of aqueous solutions on rebars was in the order $\mathrm{H}_{2} \mathrm{SO}_{4}>\mathrm{HCl}>$
$\mathrm{Na}_{2} \mathrm{SO}_{4}>\mathrm{H}_{2} \mathrm{O}$ for both imported and local bars as shown in Figures $2-8$. The ratios of the severity of local to imported steel rebars in water, $\mathrm{Na}_{2} \mathrm{SO}_{4}, \mathrm{H}_{2} \mathrm{SO}_{4}$ and $\mathrm{HCl}$ were 1.59 , $1.26,1.79$ and 1.20 respectively. Between the third and fifth week, the rate of deterioration of local steel rebars increased at a much higher rate, while those of imported bars increased at a much decreased rate. The average percentage losses in mass were $0.37 \%$ and $0.51 \%$ for imported and local bars respectively.

\subsubsection{Water $\left(\mathrm{H}_{2} \mathrm{O}\right)$}

The immersion in water value using both local and imported (Ukraine) steel rebars was presented in Figure 2.

Figure 2 reveals changes in mass of both local and imported steel bars immersed in water. Between the third and fifth week, the rate of deterioration of local steel rebars increased at a much higher rate, while those of imported bars increased at a much decreased rate. The average percentage losses in mass were $0.37 \%$ and $0.51 \%$ for imported and local bars respectively as shown in Figure 4.

\subsection{2. $\mathrm{Na}_{2} \mathrm{SO}_{4}$}

The immersion in $\mathrm{Na}_{2} \mathrm{SO}_{4}$ using both local and imported (Ukraine) steel rebars is presented in Figure 3.

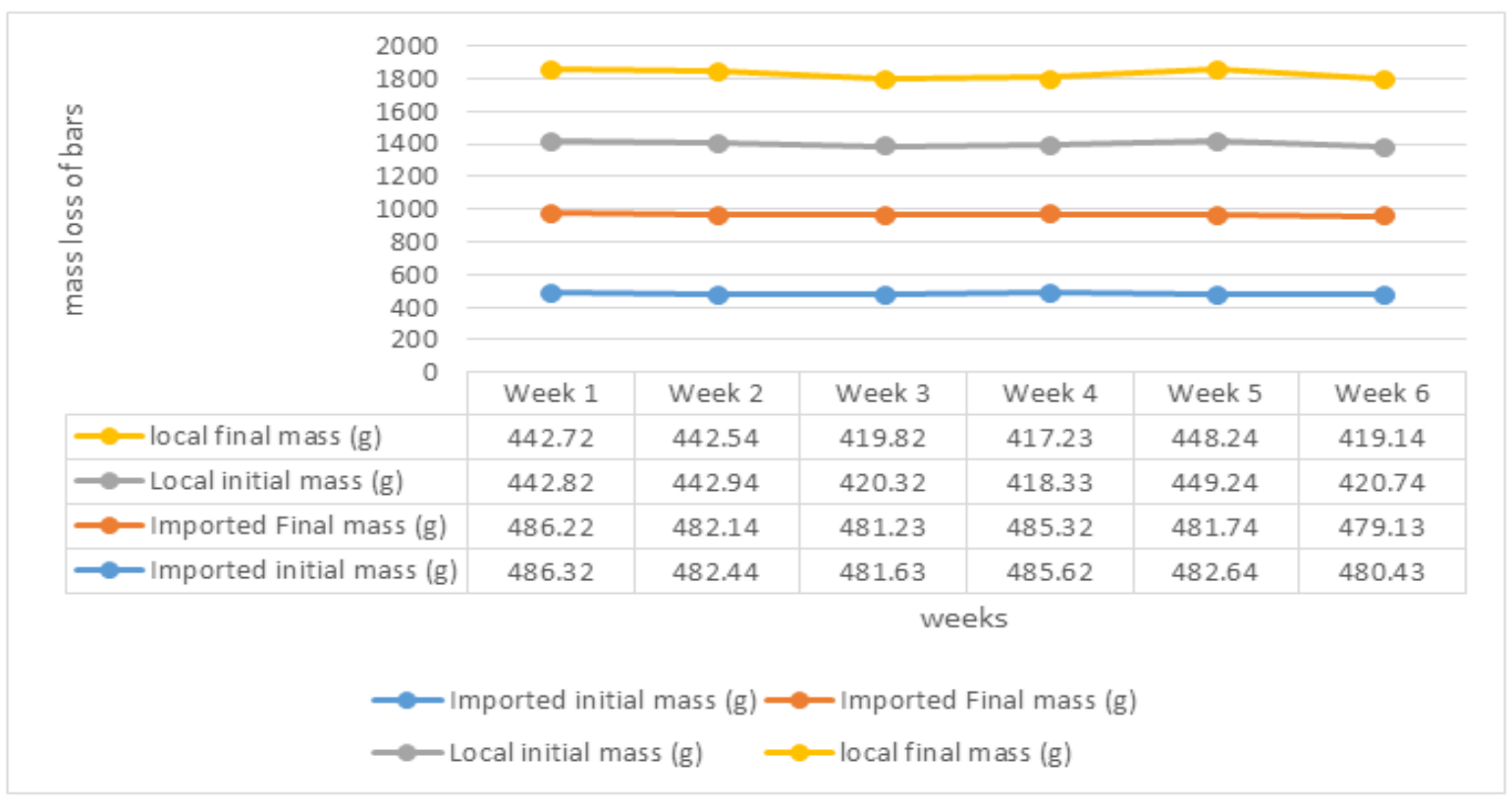

Figure 2. Change in mass of imported and local steel rebar immersed in water 


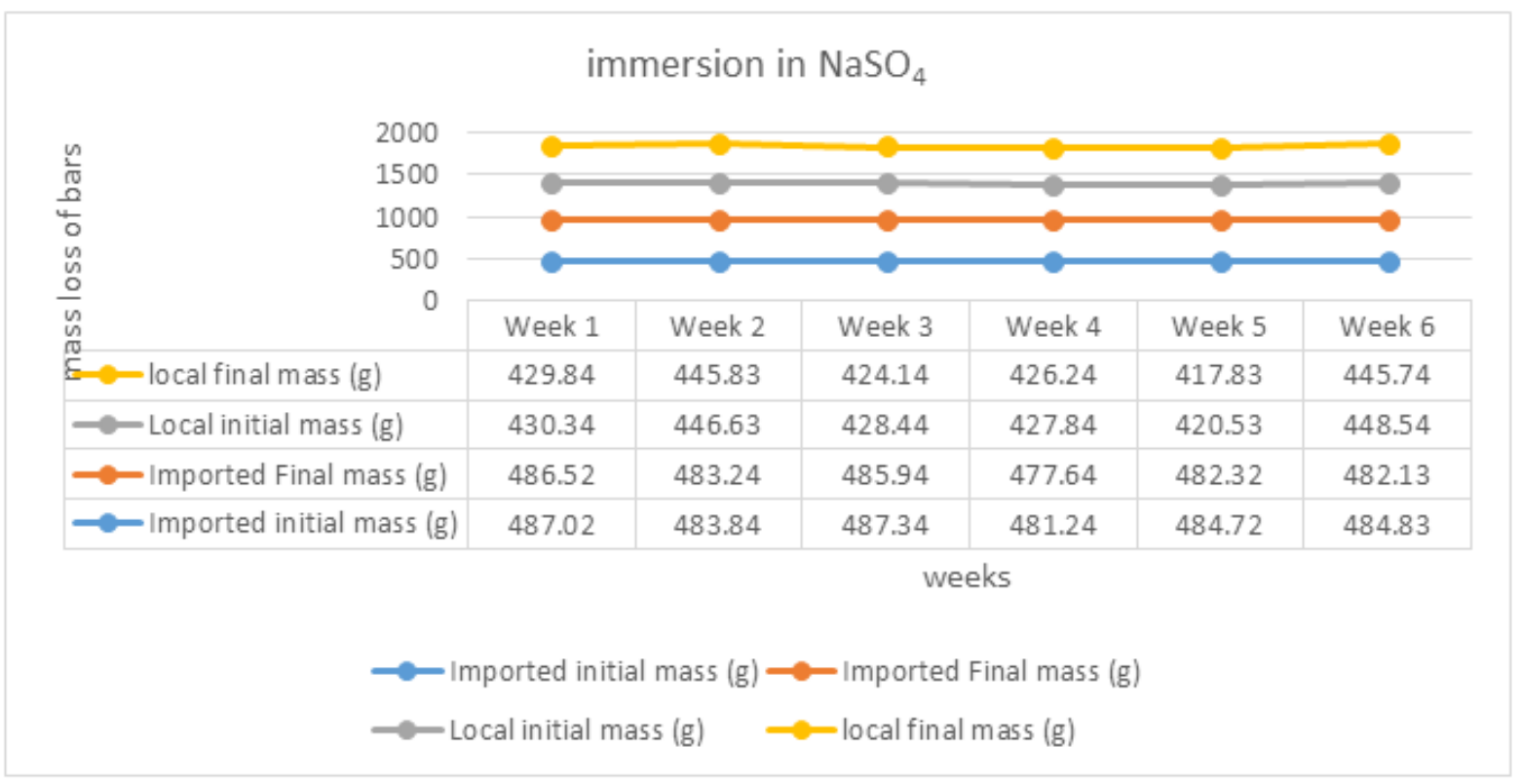

Figure 3. Change in mass of imported and local steel rebar immersed in $\mathrm{NaSO}_{4}$ solution

\begin{tabular}{|c|c|c|c|c|c|c|}
\hline \multicolumn{7}{|c|}{ immersion in different solutions } \\
\hline \multirow{3}{*}{$\begin{array}{r}2.5 \\
2 \\
1.5 \\
1 \\
0.5 \\
0\end{array}$} & \multirow{2}{*}{\multicolumn{6}{|c|}{$\stackrel{2}{2}=$}} \\
\hline & & & & & & \\
\hline & Week 1 & Week 2 & Week 3 & Week 4 & Week 5 & Week 6 \\
\hline$\longrightarrow$ Local (NaSO4) & 0.12 & 0.18 & 0.31 & 0.38 & 0.65 & 0.74 \\
\hline —Imported (NaSO4) & 0.1 & 0.12 & 0.29 & 0.33 & 0.5 & 0.56 \\
\hline —Local (water) & 0.02 & 0.09 & 0.12 & 0.26 & 0.29 & 0.38 \\
\hline$\longrightarrow$ Imported (water) & 0.02 & 0.06 & 0.08 & 0.1 & 0.19 & 0.27 \\
\hline & \multicolumn{6}{|c|}{ weeks } \\
\hline —Imported (wat & \multicolumn{2}{|c|}{$\multimap$ Local (water) } & \multicolumn{2}{|c|}{ —Imported ( $\mathrm{NaSO} 4$ ) } & \multicolumn{2}{|c|}{$\simeq$ Local (NaSO4) } \\
\hline
\end{tabular}

Figure 4. Deterioration patterns of imported and local bars different corrosive environments for water $\left(\mathrm{H}_{2} \mathrm{O}\right) \mathrm{and} \mathrm{Na}_{2} \mathrm{SO}_{4}$.

Figure 4 discloses changes in mass of both local and imported steel bars immersed in $\mathrm{Na}_{2} \mathrm{SO}_{4}$. Sodium sulphate solution $\left(\mathrm{Na}_{2} \mathrm{SO}_{4}\right)$ had a more pronounced effect on local steel rebars than that of imported steel. The rate of mass loss increases in both imported and local steel after 2 weeks and there is a noticeable deep brown colour, after 24 hour, with deposit of brownish particles at the bottom of container after 6 weeks. Though corrosion effect was almost similar at the $3 \mathrm{rd}$ week, the deterioration rate greatly increased much more for local bars than the imported category. At the end of the 6-week study, local bars had over $30 \%$ mass loss higher than the imported bars, while colours of steel changes in different solutions after a six-week period of immersion.

\subsection{3. $\mathrm{H}_{2} \mathrm{SO}_{4}$}

The immersion in $\mathrm{H}_{2} \mathrm{SO}_{4}$ values using both local and imported (Ukraine) steel rebars is presented in Figure 5. 


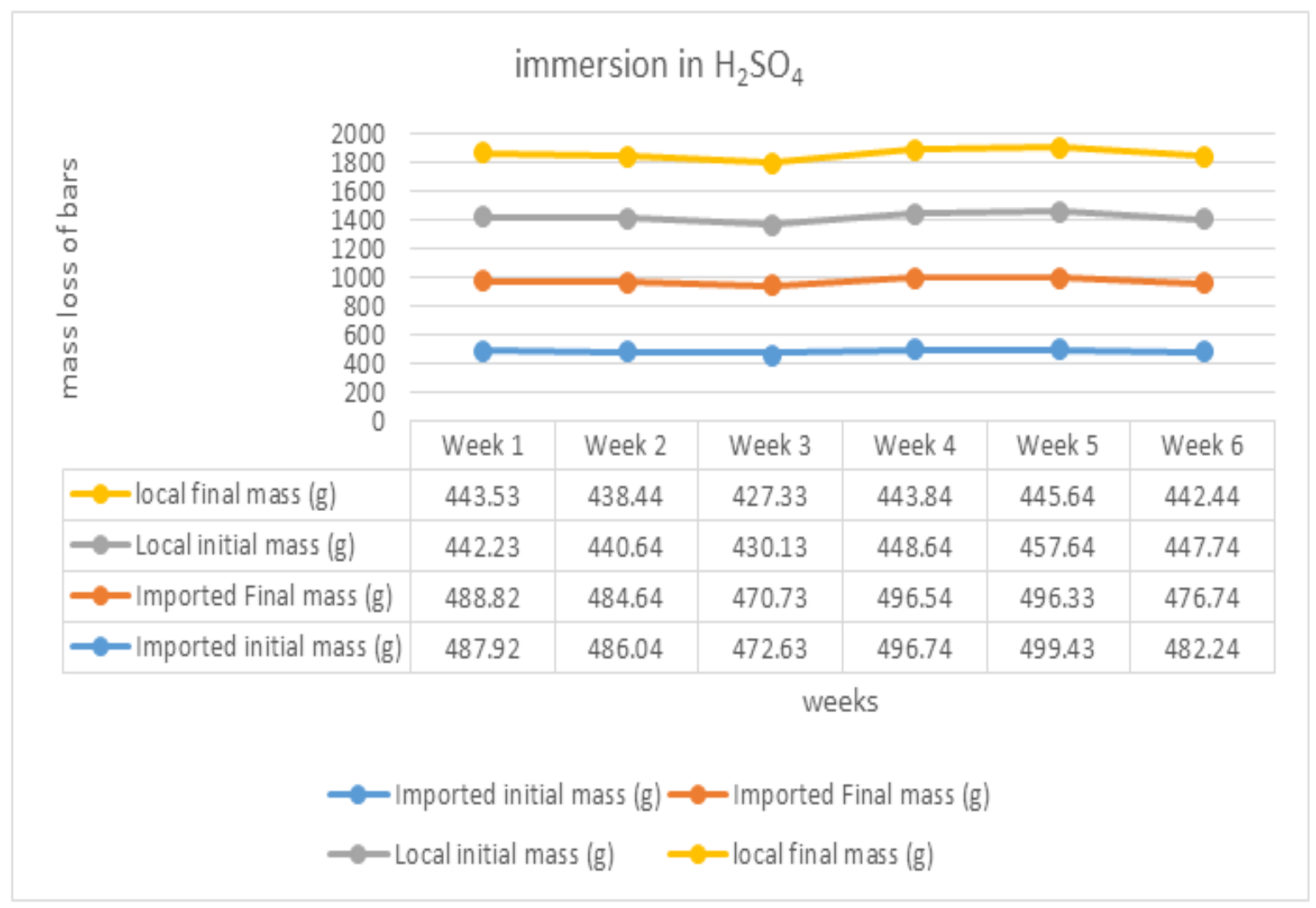

Figure 5. Change in mass of imported and local steel rebar immersed in $\mathrm{H}_{2} \mathrm{SO}_{4}$ solution.

Figure 5 indicates the trend for changes in mass of both local and imported steel bars immersed in $\mathrm{H}_{2} \mathrm{SO}_{4}$. The deterioration of steel rebar types in the corrosive environment of $\mathrm{H}_{2} \mathrm{SO}_{4}$ solution was the most severe of all the exposure environments studied. The solution on imported and local steel rebars shows bubble few hours after immersion, and the local sample appearing pale green while imported became brownish with particles at the bottom of the container. Then, within 72 hours both samples became rusty brown with more residue at the base of the container. Between the fifth and the sixth week, the colour of the solution became slightly yellowish and the specimen became reddish brown, with brownish particles deposited at the bottom of the container. Likewise, physical assessment in terms of mass loss shows a perfectly increasingly linear deterioration pattern with percentage mass loss in local bars about $80 \%$ higher than the imported bars. The widest margin was observed at the end of the 4th week when the local bars lost $143 \%$ mass higher than the imported bars. However, the margin closed up to about $9 \%$ at the end of the 6th week. The mean mass loss for local steel rebars is $3.68 \mathrm{~g}$, while the mean mass loss for imported steel rebars is $2.5 \mathrm{~g}$. Also, the local steel rebars deteriorated quickly in $\mathrm{H}_{2} \mathrm{SO}_{4}$ than the imported steel, and the rate of mass loss increases in $\mathrm{H}_{2} \mathrm{SO}_{4}$ for local and imported steel after 3rd week.

\subsection{4. $\mathrm{HCl}$}

The HC values using both local and imported (Ukraine) steel rebars are presented in Figure 6. 


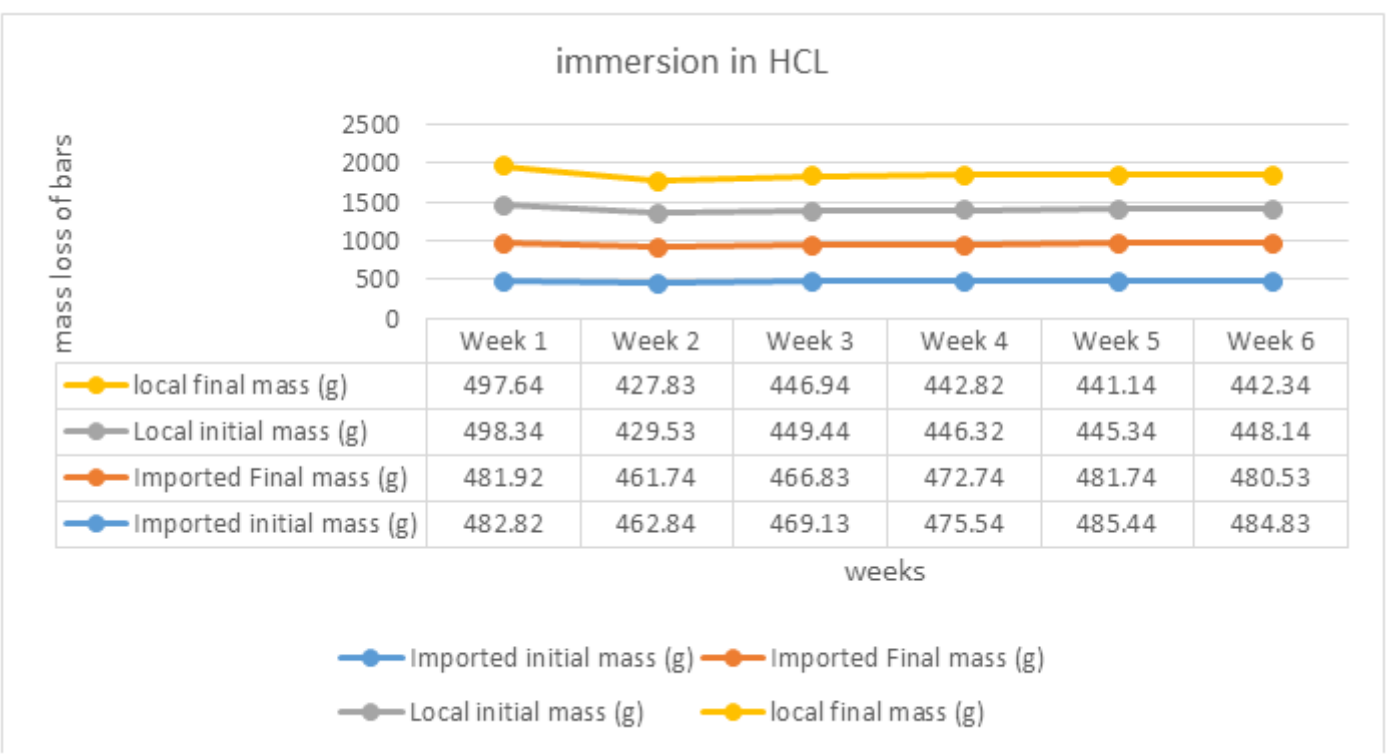

Figure 6. Change in mass of imported and local steel rebar immersed in HCL solution.

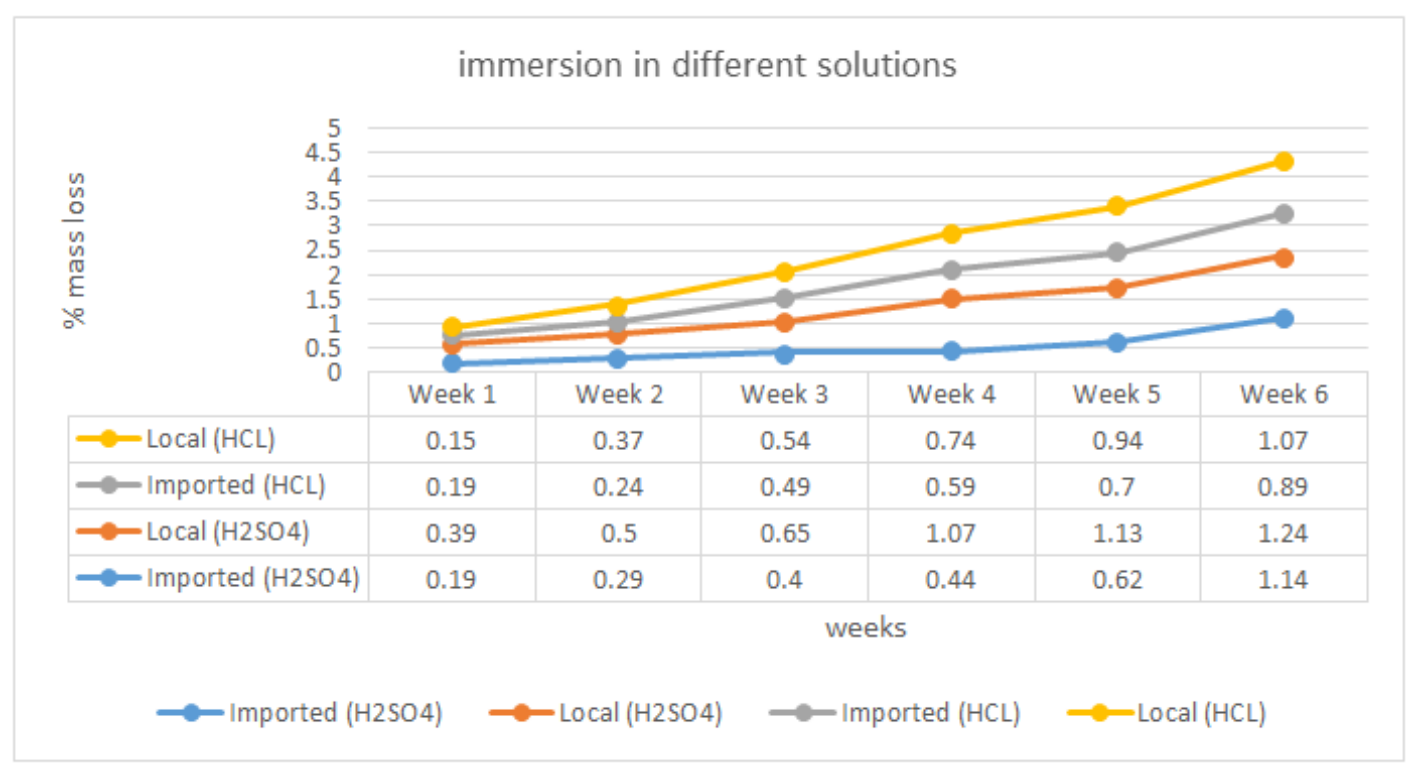

Figure 7. Deterioration patterns of imported and local bars different corrosive environments for $\mathrm{H}_{2} \mathrm{SO}_{4}$ and $\mathrm{HCl}$

Figure 6 reveals changes in mass of both local and imported steel bars immersed in $\mathrm{HCl}$, while Figure 7 shows deterioration styles for both $\mathrm{H}_{2} \mathrm{SO}_{4}$ and $\mathrm{HCl}$ immersion. The effect of hydrochloric $(\mathrm{HCl})$ acid solution on local steel rebars is more pronounced than the imported steel rebars. There is an indication of brownish colour due to effect or $\mathrm{Fe} 3+$ after few days. The colour became more reddish brown, and progressive dark brownish residues were noticed up to the end of the 6-week study. The oxidation of iron gave $\mathrm{Fe}^{2+}$ and $\mathrm{Fe}^{3+}$ and readily dissolved in $\mathrm{HCl}$ solution to form $\mathrm{FeCl}_{2}$. The rate of mass loss increased and more pronounced after the first week in $\mathrm{HCl}$ solution for both imported and local steel rebars. Then, it was observed that the local rebars deteriorate quickly in the solution than imported steel. The mean of mass loss for local steel rebars was $2.9 \mathrm{~g}$ while the mean mass loss for imported steel was $2.52 \mathrm{~g}$. At the end of the first week of study, the effect of $\mathrm{HCl}$ was about $26 \%$ more severe on the imported than the local bars in terms of percentage mass loss. However, just after the first week to the end of the 6-week investigation, the local bars increasingly suffered about $20 \%$ mass loss than the imported type. In general, the effect of $\mathrm{HCl}$ on the studied steel rebar types was the second most severe after the $\mathrm{H}_{2} \mathrm{SO}_{4}$.

\subsection{5. $\mathrm{NaOH}$}

The immersion in $\mathrm{NaOH}$ values using both local and imported (Ukraine) steel rebars was presented in Figure 8. 


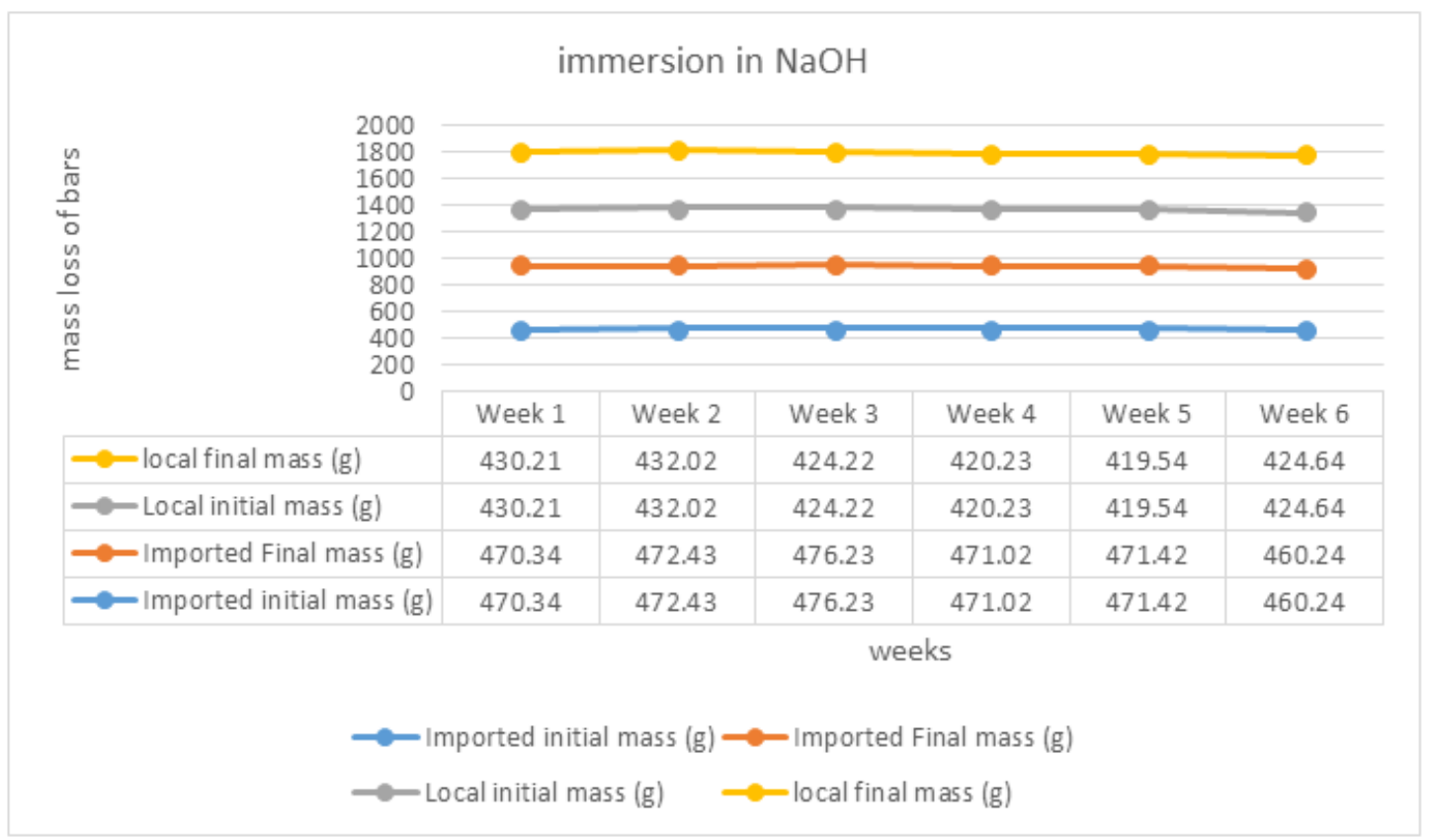

Figure 8. Change in mass of imported and local steel rebar immersed in $\mathrm{NaOH}$ solution

Figure 8 shows the trend for changes in mass of both local and imported steel bars immersed in $\mathrm{NaOH}$. The steel rebars were not affected by $\mathrm{NaOH}$ solution because no reaction took place as $\mathrm{H}+$ cannot displace $\mathrm{Na}+$ which is higher in the electrochemical series. This was confirmed as there was neither any obvious colour change nor mass loss. It is generally evident from the plots that local bars were more susceptible to corrosion than the imported bars. On the other hand, bars immersed in sodium hydroxide $(\mathrm{NaOH})$ solution maintained a slippery surface after removal from the solution. Conversely, $\mathrm{NaOH}$ is a strong base solution that shows no deterioration of steel during the 6 weeks sample study. Therefore, steel is quite safe and durable in an alkaline environment.

\section{Conclusions}

Weekly durability assessment of the rebar specimens was appraised so as to determine the mass loss and the mechanical properties when fully immersed in distilled water, and $5 \%$ solution of $\mathrm{H}_{2} \mathrm{SO}_{4}, \mathrm{HCl}, \mathrm{NaOH}, \mathrm{Na}_{2} \mathrm{SO}_{4}$ in soluble water over a total period of six weeks. The severity of aqueous solutions on rebars was in the order $\mathrm{H}_{2} \mathrm{SO}_{4}$ > $\mathrm{HCl}>\mathrm{Na}_{2} \mathrm{SO}_{4}>\mathrm{H}_{2} \mathrm{O}$ for both imported and local bars, whereas the ratios of the severity of local to imported steel rebars in water, $\mathrm{Na}_{2} \mathrm{SO}_{4}, \mathrm{H}_{2} \mathrm{SO}_{4}$ and $\mathrm{HCl}$ were $1.59,1.26$, 1.79 and 1.20 respectively. All the steel bars experienced deterioration due to mass loss characterized by colour change in all the solutions except $\mathrm{NaOH}$ solution where no visible reaction took place as $\mathrm{H}^{+}$in the aqueous solution could not display $\mathrm{Na}^{+}$which is higher in the electrochemical series. The percentage losses in mass for imported were $0.37 \%, 2.70 \%, 1.85 \%$ and $2.70 \%$, while local bars had $0.51 \%, 3.0 \%, 2.17 \%$ and $3.0 \%$ respectively. The effect of $\mathrm{HCl}$ on the studied steel rebar types was the second most severe after the $\mathrm{H}_{2} \mathrm{SO}_{4}$. The average percentage losses in mass were $0.37 \%$ and $0.51 \%$ for imported and local bars respectively. At the end of the 6-week immersion of steel bars in $\mathrm{Na}_{2} \mathrm{SO}_{4}$ solution, local bars had over 30\% mass loss higher than the imported bars. With the exception exposure of rebars specimens to $\mathrm{Na}_{2} \mathrm{SO}_{4}$ solution, the aqueous solutions were averagely about $87 \%$ more severe on imported bars than the local. Further study reveals that in Lagos metropolis, the mean bar sizes for the different diameter of rebars considered for the imported are higher in diameter than the corresponding local type, with a very small margin. Also, there is a smaller degree of uncertainty in the imported reinforcing bars size having COV in the range of 0.06 to 0.20 and the local reinforcing bars in the range of 0.25 to 0.75 for the same diameter size range. The degree of uncertainty or dispersion in the size geometry of local and imported bars is very fundamental to the development of reliable standard of practice for building civil engineering industry. Though quality Testing Boards also agreed to compare with climate condition and local standard imported steel bars (Ukraine) are below. The research can extend to chemical analysis of other foreign bars with high hardness such as Brazil reinforcement.

\section{REFERENCES}

[1] Basu P. C, Shylamoni P, Roshan A. D (2004) 
Characterisation of steel reinforcement for RC structures: An overview and related issues. Indian Concrete Journal. 78(1): 19-30.

[2] Balogh. T and L. G. Vigh. (2013), Cost Optimization of Concentric Braced Steel Building Structures. World Academy of Science, Engineering and Technology. Vol. 78, Pp. 06-21.

[3] Bellis M (2011) The History of Concrete and Cement and Concrete Research, 15(6):21-30.

[4] BS 4449 (2001) Specification for carbon steel bars for the reinforcement of concrete

[5] Castro C, Rodriguez F.J, Belzunce A. F, Canteli O (2002) Stainless Steel Rebar for Concrete Reinforcement.

[6] Chahrour A, Soudki K (2005) Flexural response of reinforce concrete beams strengthened with end -anchored partially bonded carbon fiber-reinforced polymer strips, Journal of Composites for Construction. 9(2):170-177.

[7] Clifton J. R, Mathey R. G, Anderson E.D (1999) Creep of coated Reinforcing Bars in concrete. ASCE Journal of Structural Engineering, 105 (10): 1935-1945.

[8] Clifton J.R, Marthey R.G (1983) Bond and creep characteristics of coated reinforcing bars in concrete. ASCE Journal of Structural Engineering, 80(41); 1-10.

[9] Ede A. A (2010), Building Collapse in Nigeria, International Journal for Civil and Environmental Vol. 10 No. 0632.

[10] Erhard G (2006) Designing with Plastics. African Journal of Science and Technology (AJST). 7(3):73-78.

[11] Harald Rojacz, Markus Varga, and Horst Winkelmann. (2013), Deformation Mechanisms at Elevated Temperatures: Influence of Momenta and Energy in the Single Impact Test. World Academy of Science, Engineering and Technology. Vol. 77, Pp. 05-23

[12] Hashemi S.H (2006). Analytical and experimental study of HSC members strengthened with CFRP. PhD Thesis, Kerman University, Kerman, Iran.

[13] Kankam C. K, Adom-Asamoah M (2002) Strength and ductility characteristics of reinforcing steel bars milled from scrap metals. Materials and Design, 23: 537-545.

[14] Kaushik S.K, Singh B (2002) Influence of steel-making processes on the quality of reinforcement, The Indian Concrete Journal, 76(7): 407-412.

[15] Kayali O, Zhu B (2005) Chloride induced reinforcement corrosion in lightweight aggregate High-strength fly ash concrete. Construction and Building Materials. 19,327-336

[16] Kosmatka S. H, Kerkhoff B, Panarese W. C (2003) Design and Control of Concrete Mixtures, 14th Edition. Portland Cement Association, Skokie, Illinois, USA.

[17] NIS 117 - 1992, (1992), Specification for steel bars for reinforcement of concrete. Nigerian Industrial Standards Organization of Nigeria (SON) Abuja, Nigeria.Nigerian Standard (1994) Raw Materials and Specifications for Federal Government Steel Companies, 1st Edition.

[18] Philips E. O (1998). Steel for General Structural Purposes"paper presented at the National Seminar on
Structural Codes of Practice by the Nigerian Society of Engineers (Structural Engineering Division).

[19] Yeon Tak Kim, Jong Pil Yun, Boyeul Seo, Youngsu Park, and Sang Woo Kim. (2007), A Classification Algorithm for Steel Bar in Coil using Wavelet Transform. World Academy of Science, Engineering and Technology. Vol. 9, Pp. 09-23.

[20] Alo F. I, Atanda P.O, Daniyan A. A, Abodunrin O. W, Oluwasegun K. M. (2017), An assessment of imported and local construction steel in Nigeria. Analysis by one-way ANOVA. International Journal of Materials Engineering. Vol. 7(3), Pp. 45-51. 